\title{
Inhibition of autophagy promotes cisplatin-induced apoptotic cell death through Atg5 and Beclin 1 in A549 human lung cancer cells
}

\author{
JIANHUA CHEN ${ }^{1}$, LEMENG ZHANG $^{1}$, HUI ZHOU ${ }^{2}$, WEI WANG ${ }^{1}$, \\ YONGZHONG LUO ${ }^{1}$, HUA YANG $^{1}$ and HUIHUANG YI ${ }^{1}$ \\ ${ }^{1}$ Thoracic Medicine Department $1 ;{ }^{2}$ Hematology Department, Hunan Cancer Hospital, \\ Affiliated to Xiangya Medical School, Central South University, Changsha, Hunan 410013, P.R. China
}

Received October 1, 2017; Accepted March 1, 2018

DOI: $10.3892 / \mathrm{mmr} .2018 .8686$

\begin{abstract}
Recent studies have indicated that autophagy contributes to tumorigenesis and participates in acquired chemotherapeutic resistance. The present study aimed to determine the function and underlying mechanism of cisplatin-induced autophagy in A549 human lung cancer cells. Autophagy was measured by LC3B-I/II conversion, LC3B puncta and autophagosomes formation. Apoptotic cell death was measured by caspase- 3 activity, caspase- 3 cleavage and LDH release. The transcriptional and expressional level of autophagy related proteins were measured by reverse transcription-quantitative polymerase chain reaction and western blot analysis. Beclin 1 and Atg 5 siRNA transfection was used to explore the function of cisplatin-induced autophagy. The results demonstrated that cisplatin induces apoptotic cell death in A549 cells and triggers an autophagic response, as indicated by increased microtubule-associated protein 1 light chain $3 \beta$ (LC3B)-I/II conversion, increased LC3B puncta and autophagosome formation. Mechanisms underlying cisplatin-induced autophagic responses were also investigated. Cisplatin induced autophagy by upregulating the mRNA and protein expression levels of autophagy protein (Atg) 5 and Beclin 1, whereas the mRNA and protein expression levels of serine/threonine-protein kinase ULK1, Atg3, Atg7, Atg12, and sequestosome-1 were not markedly upregulated. In addition, knockdown of Atg5 and Beclin 1 by small interfering RNA transfection impaired cisplatin-induced activation of autophagic responses, increased caspase-3 cleavage and inhibited cell viability. These findings suggested that disruption of autophagy via the inhibition of Atg5 and Beclin 1 may promote cisplatin-induced apoptotic cell death
\end{abstract}

Correspondence to: Dr Lemeng Zhang, Thoracic Medicine Department 1, Hunan Cancer Hospital, Affiliated to Xiangya Medical School, Central South University, 283 Tongzipo Road, Changsha, Hunan 410013, P.R. China

E-mail: zlmddzyx@gmail.com

Key words: autophagy, apoptosis, autophagy protein 5, Beclin 1, lung cancer in A549 human lung cancer cells. In conclusion, the present study demonstrated that targeting autophagy may be used in the future for the treatment of lung cancer.

\section{Introduction}

Lung cancer remains a leading cause of cancer-associated mortality worldwide, with an estimated 1.61 million new occurrences and 1.38 million fatalities occurring each year worldwide. In addition, the majority of patients are diagnosed at an advanced stage (1). Therefore, despite therapeutic progress, prognosis remains poor, with a 5-year survival rate of $<15 \%$ (2).

Cisplatin is a traditional first-line chemotherapy reagent (3) that causes DNA damage and apoptosis (4); however, cisplatin resistance remains an issue that contributes to recurrence and therapeutic failure. Various mechanisms underlying cisplatin resistance have been reported, including activation of DNA repair, decreased drug influx and increased efflux, and resistance to apoptosis (5). Therefore, restoring cisplatin-induced apoptosis may prevent cisplatin-acquired resistance.

Previous studies have suggested that certain chemotherapeutics induce both apoptosis and autophagy in tumor cells, and that the balance between autophagy and apoptosis may determine cell fate (6-8). Autophagy is a homeostatic, cellular process of catabolic degradation, which eliminates damaged organelles and recycles essential components during cellular stress responses (9). Autophagy serves a dual role in the tumorigenesis of lung cancer $(7,10)$; as an adaptive response, autophagy may contribute to the acquisition of cisplatin resistance in lung cancer cells (11), whereas inhibition of autophagy may resensitize tumor cells to diverse cancer therapies $(12,13)$. Conversely, autophagy-mediated cell death and autophagy-induced apoptosis have also been reported under various circumstances and among different cell types $(14,15)$. Therefore, the autophagic response may be associated with cisplatin resistance, or it may be associated with apoptotic or autophagic cell death (16); the function and mechanism of autophagy in cisplatin resistance and apoptosis remain to be elucidated.

In the present study, the function and mechanism of cisplatin-induced autophagy were investigated. Beclin 1, serine/threonine-protein kinase ULK1 (ULK1), autophagy protein (Atg)5, Atg3, Atg7, Atg12 and 
sequestosome-1 (SQSTM1) transcription and expression were analyzed following cisplatin treatment. Knockdown of Atg5 and Beclin 1 by small interfering (si)RNA transfection was used to determine the association between cisplatin-induced apoptosis and autophagy. The results indicated that specific disruption of the autophagic response may be considered a rationale for the restoration of cisplatin sensitivity, and may provide a target for anti-lung cancer therapy.

\section{Materials and methods}

Cell culture and reagents. Human lung cancer A549 cells (ATCC ${ }^{\circledR}$ CCL-185 ${ }^{\mathrm{TM}}$ ) were purchased from American Type Culture Collection (Manassas, VA, USA) and cultured as previously described (11). Cisplatin $(20 \mu \mathrm{M})$ treatment was at $37^{\circ} \mathrm{C}$ in an atmosphere containing $5 \% \mathrm{CO}_{2}$ for the indicated time points in Fig. 1. Cisplatin, MTT and the lactate dehydrogenase (LDH)-dependent Cytotoxic Non-Radioactive Cytotoxicity assay were purchased from Promega Corp. (Madison, WI, USA). The Caspase-3 Fluorometric Assay kit was purchased from BioVision, Inc. (Milpitas, CA, USA). Microtubule-associated protein 1 light chain $3 \beta$ (LC3B) antibody was obtained from Novus Biologicals, LLC, Littleton, CO, USA (cat. no. NB100-2220), and Beclin 1 (cat. no. 3738), Atg5 (cat. no. 2630), cleaved caspase-3 (cat. no. 9661), Atg3 (cat. no. 3415), Atg7 (cat. no. 2631) and Atg12 (cat. no. 4180) antibodies were from Cell Signaling Technology, Inc. (Danvers, MA, USA). SQSTM1 antibody (cat. no. M217-3) was purchased from MBL International Co. (Woburn, MA, USA), and ULK1 (cat. no. A7481) and $\beta$-actin (cat. no. A5441) antibodies were obtained from Sigma-Aldrich (Merck KGaA, Darmstadt, Germany). Goat anti-rabbit secondary antibody (cat. no. A-11037) was from Thermo Fisher Scientific, Inc. (Waltham, MA, USA).

Reverse transcription-quantitative polymerase chain reaction $(R T-q P C R)$. Total RNA was extracted by using TRIzol reagent (Invitrogen; Thermo Fisher Scientific, Inc.), according to the manufacturer's protocol. CDNA was synthesized using a PrimeScript RT Reagent kit (Takara Bio, Inc., Otsu, Japan). The PCR reaction was performed with SYBR ${ }^{\circledR}$ Green Master Mix (Ambion; Thermo Fisher Scientific, Inc.) in an ABI 7500 RT-PCR System (Applied Biosystems; Thermo Fisher Scientific, Inc.). Primers were synthesized by Invitrogen (Thermo Fisher Scientific, Inc.; listed in Table I), as described previously (17). Amplification was performed under the following conditions: $95^{\circ} \mathrm{C}$ for $5 \mathrm{~min}$ in the holding stage; 40 cycles of $95^{\circ} \mathrm{C}$ for $10 \mathrm{sec}$ and $60^{\circ} \mathrm{C}$ for $30 \mathrm{sec}$ in the cycling stage; and $95^{\circ} \mathrm{C}$ for $15 \mathrm{sec}, 60^{\circ} \mathrm{C}$ for $1 \mathrm{~min}$ and $60^{\circ} \mathrm{C}$ for $15 \mathrm{sec}$ in the melt curve stage. Relative gene expression was calculated using the comparative $2^{-\Delta \Delta \mathrm{Cq}}$ method (18). The mean $\mathrm{Cq}$ value of the target gene was normalized to the averaged $\mathrm{Cq}$ values of GAPDH to obtain a $\Delta \mathrm{Cq}$ value, which was subsequently normalized to control samples to obtain a $\Delta \Delta \mathrm{Cq}$ value. Each measurement was assessed in triplicate. The gene expression ratio was presented as the mean \pm standard deviation of three independent experiments.

Western blot analysis. Cytoplasmic protein expression in cultured cells was detected using western blotting as previously described (19). Membranes were incubated overnight at $4^{\circ} \mathrm{C}$ using primary antibodies diluted in $1 \%$ bovine serum albumin. LC3B, Beclin 1, ULK1, Atg5, cleaved caspase-3, Atg3, Atg7 and Atg12 primary antibodies were diluted at 1:1,000. SQSTM1 primary antibody was diluted at 1:2,000. The secondary antibodies were diluted at 1:5,000 and were incubated at room temperature for $1 \mathrm{~h}$.

siRNA transfection. Beclin 1 and Atg5 siRNA were purchased from Santa Cruz Biotechnology, Inc. (Dallas, TX, USA). The recombinant lentiviral vectors, empty lentiviral vectors and secondary packaging plasmids were co-transfected into the 293T cells using Lipofectamine ${ }^{\circledR} 2000$ (Invitrogen; Thermo Fisher Scientific, Inc.), according to the manufacturer's protocols. The obtained Beclin 1 and Atg 5 siRNA particle solutions were designated as Lv-si8678 and Lv-si9474 and the $\mathrm{Lv}$-control and were stored at $-80^{\circ} \mathrm{C}$ until use. The sequences of Beclin1, Atg5 and negative control were: 5'-CAGTTTGGC ACAATCAATA-3', 5'-AUCCAUGAGUUUCCGAUUC-3' and 5'-UUCUCCGAACGUGUCAGUT-3', respectively. Transfection of cells with $100 \mathrm{nM}$ siRNA was performed using Lipofectamine ${ }^{\circledR} 2000$ (Invitrogen; Thermo Fisher Scientific, Inc.) according to a previously published method (20).

Cell viability, $L D H$ release and caspase-3 activity assays. Cell viability was measured using the MTT assay according to the manufacturer's protocol (Promega Corp.). LDH release into the culture medium was measured using the LDH-dependent Cytotoxic Non-Radioactive Cytotoxicity Assay and caspase-3 activity was measured with a Caspase-3 Fluorometric Assay kit, both according to manufacturers' protocols.

Transmission electron microscopy (TEM). For TEM, cells were embedded, sectioned, double stained and analyzed using a JEM-1200EX transmission electron microscope (JEOL, Ltd., Tokyo, Japan), as previously described (20).

Immunofluorescence staining. Human lung cancer A549 cells (ATCC ${ }^{\circledR}$ CCL-185 $\left.{ }^{\mathrm{TM}}\right)$ were treated with cisplatin $(20 \mu \mathrm{M})$ for $96 \mathrm{~h}$ at $37^{\circ} \mathrm{C}$ in an atmosphere containing $5 \% \mathrm{CO}_{2}$. LC3B puncta were measured using immunofluorescence, as previously described (20).

Statistical analysis. All values are presented as the means \pm standard deviation $(n=3)$. Quantitative data were analyzed using a Student's t test or two-way analysis of variance (ANOVA), with a Tukey post hoc test used following ANOVA, by using SPSS software (version 16.0; SPSS, Inc., Chicago, IL, USA). $\mathrm{P}<0.05$ was considered to indicate a statistically significant difference.

\section{Results}

Cisplatin leads to apoptotic cell death in A549 cells. Cleavage and activation of caspase- 3 is necessary for the execution phase of intrinsic and extrinsic apoptotic signaling pathways (21). In the present study, cisplatin inhibited A549 human cancer cell viability (Fig. 1A) and increased LDH release (Fig. 1B). Cisplatin also promoted cleavage (Fig. 1C) and activation (Fig. 1D) of capase-3 following cisplatin treatment in a 

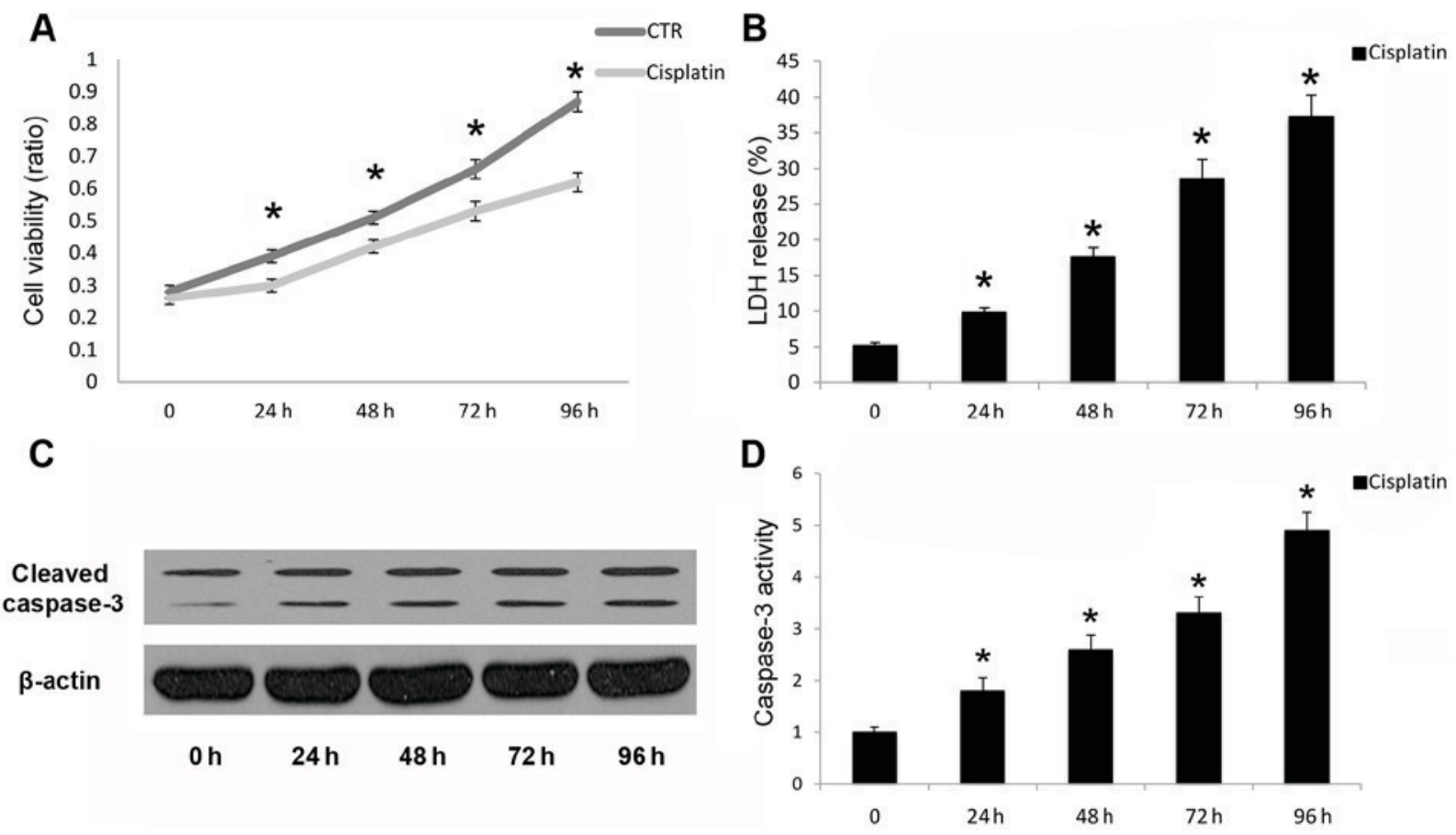

Figure 1. Cisplatin leads to apoptotic cell death in A549 cells. A549 cells were treated with cisplatin $(20 \mu \mathrm{M})$ for the indicated time periods. (A) Cell viability and (B) LDH release were detected following cisplatin treatment. (C) Caspase-3 cleavage following cisplatin treatment was measured by western blotting. (D) Caspase-3 activity following cisplatin treatment. ${ }^{\mathrm{P}}<0.05$ vs. the CTR group $(0 \mathrm{~h})$. CTR, control; $\mathrm{LDH}$, lactate dehydrogenase.

time-dependent manner up to $96 \mathrm{~h}$. Reduced cell viability and promotion of cell death were due to the induction of apoptosis, as demonstrated by caspase-3 cleavage and activation. Therefore, cisplatin may induce apoptotic cell death in A549 cells in a time-dependent manner.

Cisplatin initiates the autophagic response in A549 cells. Cellular stress responses, caused by factors including exposure to anticancer drugs, can trigger the autophagic response (22). Kinetic analysis of autophagosome formation in A549 cells demonstrated that cisplatin-induced autophagy occurs in a time-dependent manner. Western blot analysis indicated an increased LC3B-I/II conversion following cisplatin treatment up to $96 \mathrm{~h}$ (Fig. 2A). Densitometry was performed by Image J to quantify OD; increased LC3B-I/II conversion indicated that autophagosome formation was upregulated. The ratio of LC3B-I/II conversion for each group was 0.34 (control), 0.45 (24 h), 0.56 (48 h), 0.69 (72 h) and 0.78 (96 h).

Autophagy occurred in A549 cells treated with cisplatin, as demonstrated by increased LC3B puncta (Fig. 2B and C). In addition, cisplatin-induced morphological alterations were observed by TEM, including the formation of double membrane-bound autophagosomes and mitochondrial damage (Fig. 2D and E). These specific alterations in LC3B have been characterized as autophagosome markers. Therefore, the results of the present study indicated that cisplatin triggers the autophagic response in A549 cells.

Cisplatin induces the autophagic response in A549 cells by upregulating $m R N A$ and protein levels of Atg 5 and Beclin 1. The signaling pathways that mediate autophagic induction differ according to cell type and stimulus (23). The mechanism underlying cisplatin-mediated autophagy in A549 cells remains to be elucidated. Therefore, the present study investigated the mechanism underlying cisplatin-induced autophagy in A549 cells. Beclin 1, Atg5, ULK1, Atg3, Atg7, Atg12 and SQSTM1 mRNA and protein levels were measured following cisplatin treatment. Induction of autophagy following cisplatin treatment resulted in increased transcription of certain autophagy-associated genes, including Atg5 and Beclin 1 (Fig. 3A). However, the expression of other autophagy-associated genes was not significantly altered (Fig. 3A). Autophagy-associated gene expression analysis indicated that cisplatin induced autophagy through upregulation of Beclin 1 and Atg5 (Fig. 3B), without altering the expression of other autophagy-associated proteins (Fig. 3C). Atg5 and Beclin 1 expression levels were continuously increased following cisplatin treatment. Therefore, Atg5 and Beclin1 transcriptional and translational upregulation may be involved in cisplatin-induced autophagy in A549 lung cancer cells.

Inhibition of autophagy by Atg5 and Beclin 1 siRNA transfection promotes cisplatin-induced apoptosis of A549 cells. Subsequently, it was investigated whether autophagy resulted in cell death, or exerted protective effects following cisplatin treatment in A549 cells. Knockdown of Atg5 by siRNA transfection impaired cisplatin-induced Atg 5 activation and therefore inhibited the activation of autophagy, and promoted caspase-3 cleavage (Fig. 4A). Inhibition of autophagy through knockdown of Atg5 (Fig. 4B) also inhibited cell viability and led to increased LDH release (Fig. 4C). Similarly, knockdown of Beclin 1 inhibited cisplatin-induced Beclin 1 activation and autophagosome formation (Fig. 5A). Decreased LC3B-I/II conversion indicated that autophagosome formation was inhibited. Beclin 1 knockdown markedly promoted 
Table I. Primer pairs for quantitative polymerase chain reaction.

Primer sequence $\left(5^{\prime} \rightarrow 3^{\prime}\right)$

\begin{tabular}{lll}
\cline { 2 - 3 } Target name & \multicolumn{1}{c}{ Forward } & \multicolumn{1}{c}{ Reverse } \\
\hline Beclin 1 & CAAGATCCTGGACCGTGTACA & TGGCACTTTCTGTGGACATCA \\
Atg12 & TCTATGAGTGTTTTGGCAGTG & ATCACATCTGTTAAGTCTCTTGC \\
Atg7 & AGGAGATTCAACCAGAGACC & GCACAAGCCCAAGAGAGG \\
Atg5 & GGGAAGCAGAACCATACTATTTG & AAATGTACTGTGATGTTCAAGG \\
Atg3 & TCACAACACAGGTATTACAGG & TCACCGCCAGCATCAG \\
ULK1 & CGCCTGTTCTACGAGAAGAAC & GAAGTCCATGCGGTCCTTGTG \\
SQSTM1 & AAGCCGGGTGGGAATGTTG & GCTTGGCCCTTCGGATTCT \\
GAPDH & GGGAAGCTTGTCATCAATGG & CATCGCCCCACTTGATTTTG
\end{tabular}

Atg, autophagy protein; SQSTM1, sequestosome-1; ULK1, serine/threonine-protein kinase ULK1.

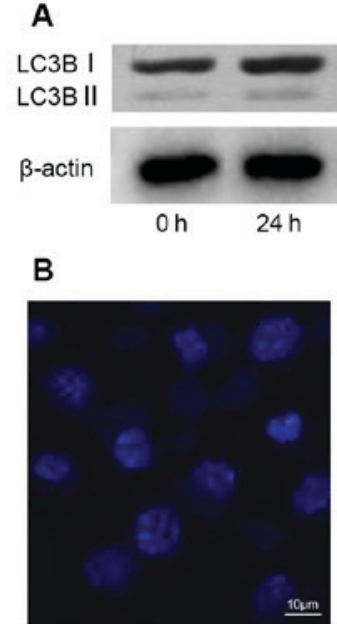

CTR

D

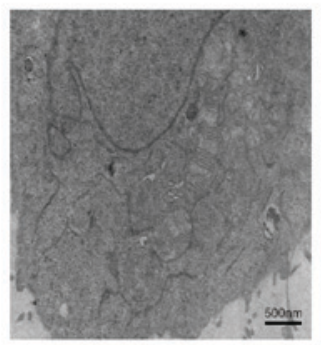

CTR

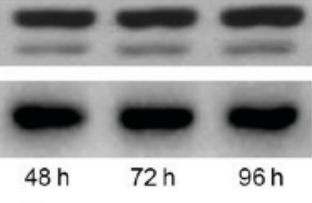

C

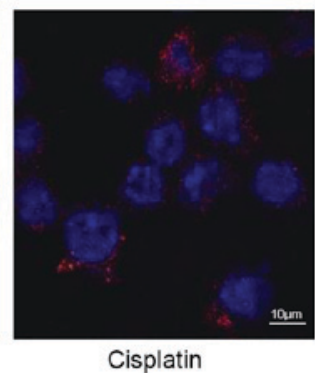

E

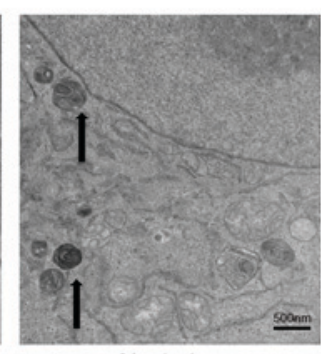

Cisplatin
Figure 2. Cisplatin triggers the autophagic response in A549 cells. (A) A549 cells were treated with cisplatin $(20 \mu \mathrm{M})$ and LC3B-I/II conversion was measured by western blotting. (B and C) A549 cells were treated with cisplatin $(20 \mu \mathrm{M})$ for $96 \mathrm{~h}$ and LC3B puncta were measured using immunofluorescence. The blue is DAPI for DNA staining and the red is LC3B puncta staining for autophagosomes. (D and E) A549 cells were treated with cisplatin $(20 \mu \mathrm{M})$ for $96 \mathrm{~h}$ and morphological alterations of double membrane-bound autophagosomes were assessed with transmission electron microscopy. The arrows indicate the formation of double membrane-bound autophagosomes. CTR, control; LC3B, microtubule-associated protein 1 light chain $\beta$.

cisplatin-induced caspase-3 cleavage (Fig. 5A), inhibited cell viability (Fig. 5B) and led to increased LDH release (Fig. 5C). Therefore, knockdown of Atg5 and Beclin 1 by siRNA may impair the cisplatin-induced activation of autophagy, promote

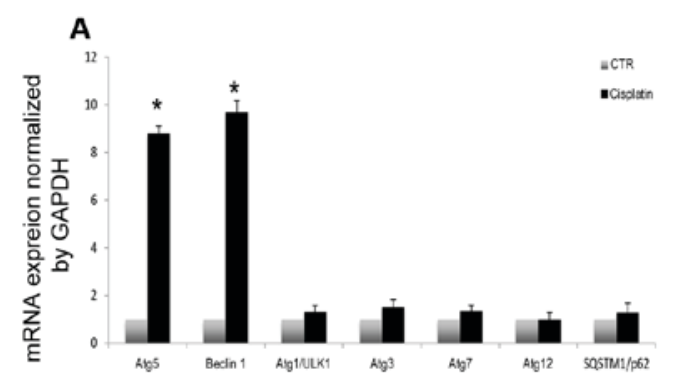

B
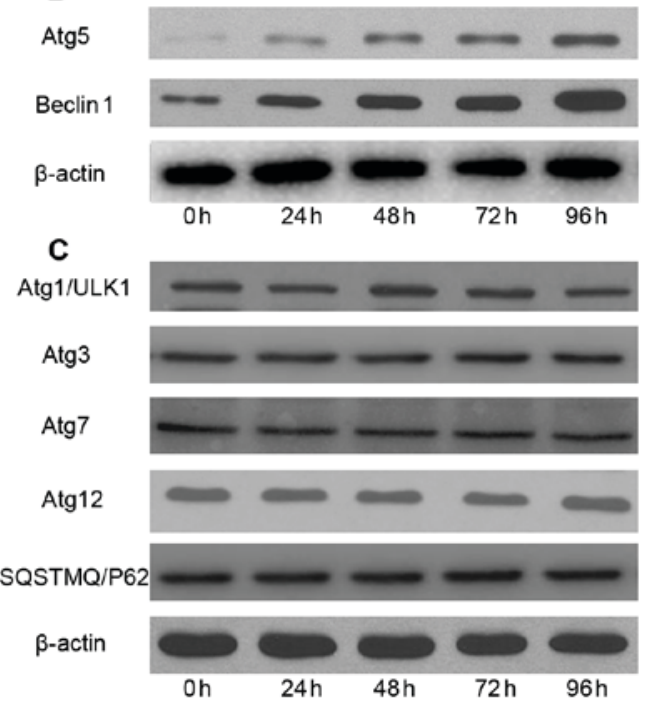

Figure 3. Cisplatin-induced autophagic response involves upregulation of Atg5 and Beclin 1. (A) A549 cells were treated with cisplatin $(20 \mu \mathrm{M})$ for $24 \mathrm{~h}$, and Beclin 1, Atg5, ULK1, Atg3, Atg7, Atg12 and SQSTM1 transcription were analyzed by reverse transcription-quantitative polymerase chain reaction. A549 cells were treated with cisplatin $(20 \mu \mathrm{M})$ at the indicated time points, and (B) Beclin 1 and Atg5, and (C) ULK1, Atg3, Atg7, Atg12 and SQSTM1 expression levels were measured by western blotting. "P $<0.05$ vs. the CTR group. Atg, autophagy protein; CTR, control; SQSTM1, sequestosome-1; ULK1, serine/threonine-protein kinase ULK1.

caspase-3 cleavage and lead to increased cell death. Disruption of autophagy through the knockdown of Atg 5 and Beclin 1 may promote cisplatin-induced apoptotic cell death in A549 cells. 


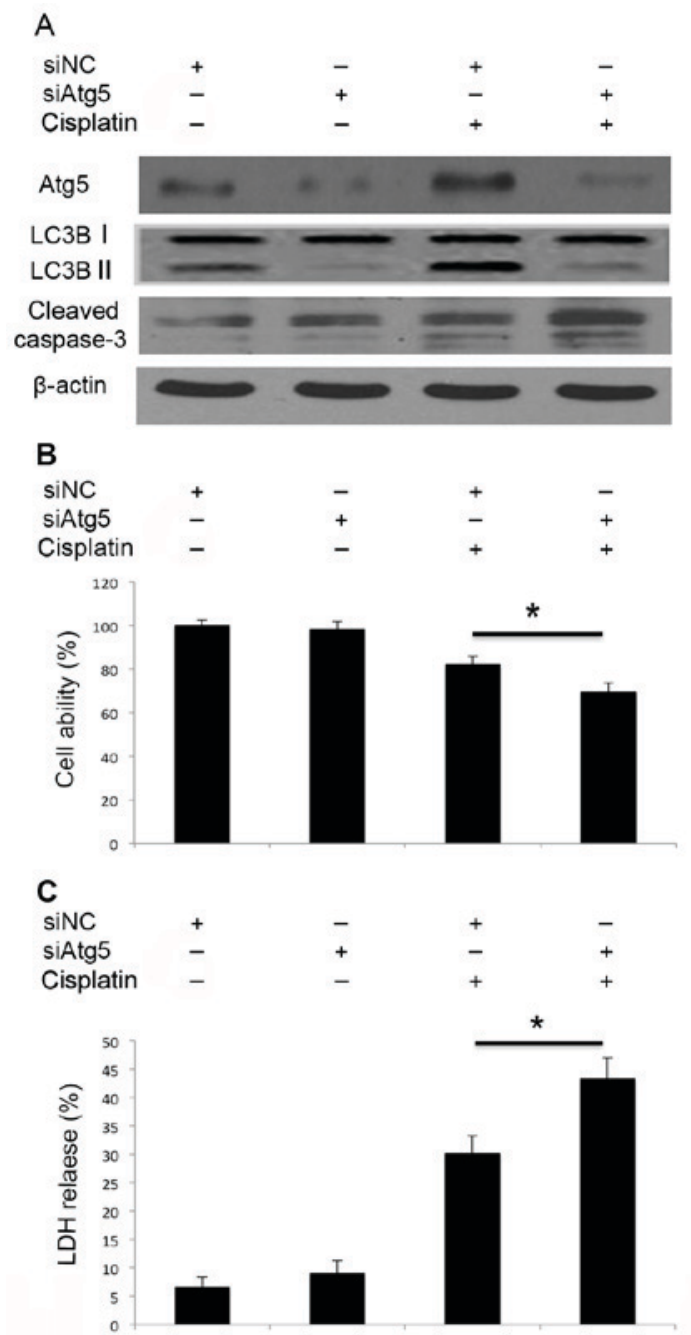

Figure 4. Inhibition of autophagy by Atg 5 siRNA promotes cisplatin-induced apoptosis of A549 cells. A549 cells were transfected with $100 \mathrm{nM}$ Atg5 siRNA for $16 \mathrm{~h}$ and were treated with cisplatin $(20 \mu \mathrm{M})$ for $48 \mathrm{~h}$. (A) Atg5 expression, caspase-3 cleavage and LC3B-I/II conversion was measured by western blotting. (B) Cell viability and (C) $\mathrm{LDH}$ release were measured using commercial kits. "P<0.05. Atg, autophagy protein; LC3B, microtubule-associated protein 1 light chain $3 \beta$; LDH, lactate dehydrogenase; NC, negative control; si/siRNA, small interfering RNA.

\section{Discussion}

A limited number of patients with lung cancer diagnosed at a metastatic stage survive $>5$ years. Cisplatin-based combination chemotherapy is used to extend the survival of patients with advanced lung cancer; however, the majority of patients relapse within 1 year, primarily due to acquired resistance $(24,25)$. Therefore, increasing the sensitivity of cancer cells to cisplatin is desired. Restoring cisplatin-induced apoptosis may be an effective strategy for overcoming chemotherapeutic resistance. The present study aimed to elucidate the mechanism and function underlying cisplatin-induced autophagy in A549 lung cancer cells, using genetic knockdown of autophagy-associated genes to provide a potential target for improvement of sensitivity to chemotherapeutic drugs.

Previous studies indicated reciprocal regulation between autophagy and apoptosis in tumor cell survival following chemotherapy $(11,26)$. Modulation of autophagy may affect
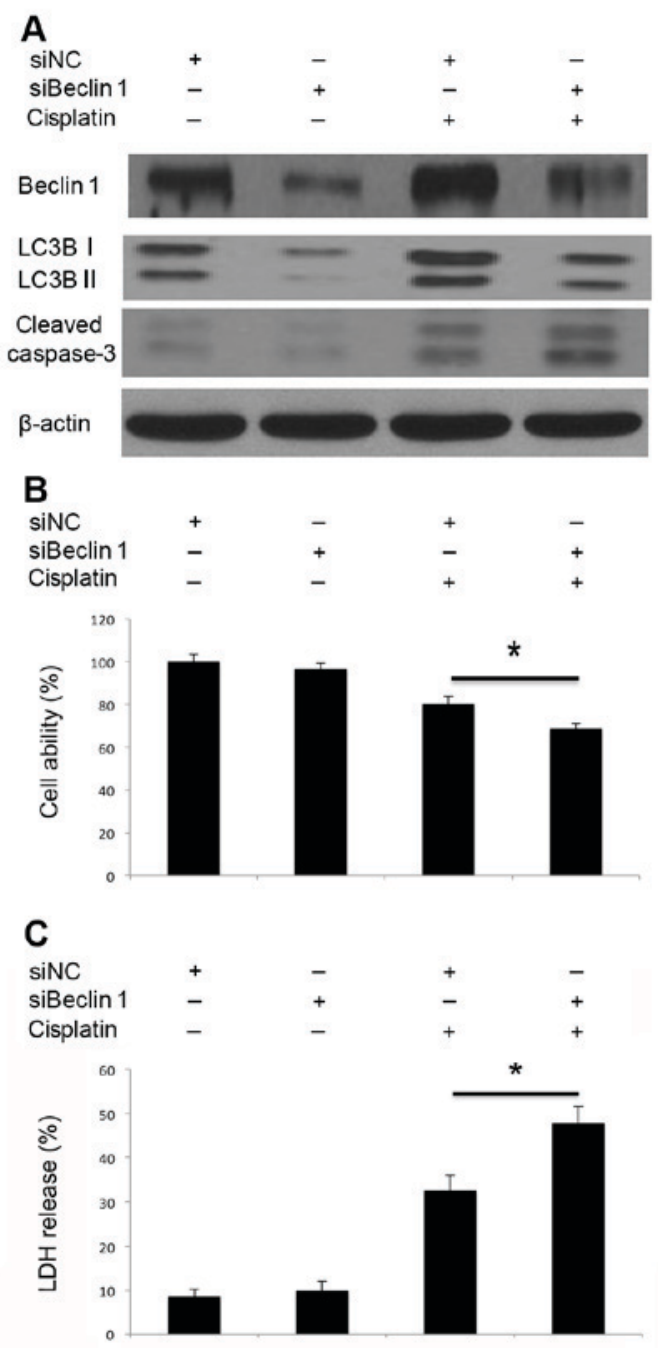

Figure 5. Inhibition of autophagy by Beclin 1 siRNA promotes cisplatin-induced apoptosis of A549 cells. A549 cells were transfected with $100 \mathrm{nM}$ Beclin 1 siRNA for $16 \mathrm{~h}$ and treated with cisplatin $(20 \mu \mathrm{M})$ for $48 \mathrm{~h}$. (A) Beclin 1 expression, caspase-3 cleavage and LC3B-I/II conversion was measured by western blotting. (B) Cell viability and (C) $\mathrm{LDH}$ release were measured using commercial kits. ${ }^{*} \mathrm{P}<0.05$. LC3B, microtubule-associated protein 1 light chain $3 \beta$; LDH, lactate dehydrogenase; $\mathrm{NC}$, negative control; si/siRNA, small interfering RNA.

apoptosis of cancer cells. The present study demonstrated that cisplatin induced apoptosis and autophagy in human lung cancer cells. Subsequently, it was further investigated whether inhibition of autophagy would result in an increased rate of apoptosis.

A previous study demonstrated that upregulation of autophagy contributes to cisplatin resistance in human lung cancer cells (11). Inhibition of autophagy, either by pharmacological inhibitors or by genetic knockdown of autophagy-associated genes, may enhance chemotherapy-induced cytotoxicity. In addition, inhibition of autophagy may lead to the accumulation of reactive oxygen species in cisplatin-treated lung cancer cells, and suppression of autophagy may sensitize cells to cisplatin-induced caspase-dependent and -independent apoptosis (27). Combination treatment using autophagic inhibitors can potentiate the efficacy of epidermal growth factor receptor-targeted cancer therapeutics (28). Furthermore, 
inhibition of autophagy promotes paclitaxel-induced apoptosis (29). In all of these aforementioned cases, autophagy was protective and prevented lung cancer cells from undergoing apoptosis; however, if cellular damage is extensive, or if apoptosis is compromised, autophagic cell death may occur $(14,15)$. Previous studies presented conflicting results regarding the function of autophagy in cancer chemotherapy; in certain studies autophagy promotes cell survival, and in other, induces autophagic cell death $(22,30)$. The present study demonstrated that inhibition of autophagy enhanced the cytotoxicity of cisplatin. The results of the present study indicated that autophagy may serve a protective role and may participate in cisplatin-acquired resistance. Cisplatin upregulated Atg5 and Beclin 1 mRNA and protein expression; however, the expression levels of other autophagy-associated genes were not altered by cisplatin. Therefore, the present study further investigated the role of Atg5 and Beclin 1 in cisplatin-induced autophagy and apoptosis.

Apoptosis and autophagy interact via crosstalk (31) and each may occur simultaneously or sequentially $(32,33)$. Autophagy and apoptosis are distinct processes but an overlapping mechanism may regulate both. Beclin 1, Atg5, Atg7 and high-mobility group box 1 are involved in the regulation of apoptosis and autophagy $(17,34)$. Formation of the Atg12-Atg5 conjugate is necessary for autophagosome formation and autophagy mediates cisplatin resistance under hypoxia through Atg5 (35). Tissue-specific knockdown of Atg5 markedly impairs mitochondrial energy homoeostasis and leads to oxidative stress and constitutively active DNA damage (10). Inhibition of Atg5 sensitizes resistant carcinoma cells to radiotherapy and certain chemotherapeutic reagents $(31,36,37)$. However, Atg5 is not involved in gefitinib- or erlotinib-induced autophagy (38). The present study demonstrated that Atg5 is involved in cisplatin-induced autophagy, and inhibition of autophagy by knocking down Atg5 significantly enhanced cisplatin-induced apoptosis.

Beclin 1 initiates autophagy by forming a Beclin 1-phosphatidylinositol 3-kinase III/Vps34 complex. Previous studies demonstrated that decreased expression of Beclin 1 is associated with tumor progression in lung, colon and ovarian cancer (39-41), and reduced Beclin 1 expression is a predictor of poor prognosis for gastric and lung cancer $(42,43)$. The carcinogenic mechanism of Beclin 1 downregulation in cancer may be associated with apoptosis. In a previous study, eliminating Beclin 1 protein resulted in stimulation of the apoptotic pathway in DNA-damaged breast cancer cells (44). Beclin 1 overexpression may also contribute to inhibition of lung cancer cell growth, angiogenesis and inhibition of apoptosis during radiotherapy (45). Beclin 1 plays a dual role in tumorigenesis. In the present study, Beclin 1 knockdown inhibited cisplatin-induced autophagy and promoted cisplatin-induced apoptotic cell death. However, the function of Beclin 1 overexpression, whether protective or detrimental, is dependent on the specific tumor type, stage and circumstances. The present study demonstrated that knockdown of Beclin 1 promoted sensitivity of lung cancer cells to chemotherapy and increased apoptotic cell death.

Inhibition of autophagy promotes genomic instability, interferes with cellular differentiation, perturbs cellular metabolism, and prevents resistance to chemotherapy or radiotherapy (46). The present study demonstrated that inhibition of autophagy, through knockdown of Atg5 and Beclin 1, may promote cisplatin-induced apoptotic cell death. However, the expression and clinical application of modulation of Atg5 and Beclin 1 in patients with lung cancer should be further confirmed by large sample cohort studies. Furthermore, in vivo studies investigating the functions and downstream effectors of Atg5 and Beclin 1 are required, as are further studies investigating the association between Atg5, Beclin 1 and genomic instability, cellular differentiation, mitochondrial energy homeostasis, and efficacy of chemotherapy and radiotherapy.

In conclusion, the present study demonstrated that cisplatin can induce apoptosis and autophagy in human lung cancer cells in vitro. Inhibition of autophagy via the knockdown of Atg5 and Beclin 1 promoted cisplatin-induced apoptosis. The results of the present study suggested that targeting autophagy-associated pathways may be considered a therapeutic strategy to overcome cisplatin resistance by inducing apoptosis. The present study suggested a rationale for modulating autophagy to treat lung cancer.

\section{Acknowledgements}

Not applicable.

\section{Funding}

The present study was supported by a grant from the National Natural Science Foundation of China (grant no. 81401631).

\section{Availability of data and materials}

All data generated or analyzed during this study are included in this published article.

\section{Authors' contributions}

JC and LZ conceived and designed the experiments; HZ, WW and YL performed the experiments and contributed to molecular analysis; $\mathrm{HY}$ and $\mathrm{H}-\mathrm{hY}$ analyzed the data; $\mathrm{LZ}$ wrote the manuscript.

\section{Ethics approval and consent to participate}

Not applicable.

\section{Consent for publication}

Not applicable.

\section{Competing interests}

The authors declare that they have no competing interests.

\section{References}

1. Jemal A, Bray F, Center MM, Ferlay J, Ward E and Forman D: Global cancer statistics. CA Cancer J Clin 61: 69-90, 2011.

2. Awala H, Gilson JP, Retoux R, Boullay P, Goupil JM, Valtchev V and Mintova S: Template-free nanosized faujasite-type zeolites. Nat Mater 14: 447-451, 2015. 
3. Fennell DA, Summers Y, Cadranel J, Benepal T, Christoph DC, Lal R, Das M, Maxwell F, Visseren-Grul C and Ferry D: Cisplatin in the modern era: The backbone of first-line chemotherapy for non-small cell lung cancer. Cancer Treat Rev 44: 42-50, 2016.

4. Dasari S and Tchounwou PB: Cisplatin in cancer therapy: Molecular mechanisms of action. Eur J Pharmacol 740: 364-378, 2014.

5. Galluzzi L, Vitale I, Michels J, Brenner C, Szabadkai G, Harel-Bellan A, Castedo M and Kroemer G: Systems biology of cisplatin resistance: Past, present and future. Cell Death Dis 5: e1257, 2014.

6. Mariño G, Niso-Santano M, Baehrecke EH and Kroemer G: Self-consumption: The interplay of autophagy and apoptosis. Nat Rev Mol Cell Biol 15: 81-94, 2014.

7. White E: Deconvoluting the context-dependent role for autophagy in cancer. Nat Rev Cancer 12: 401-410, 2012.

8. Ouyang L, Shi Z, Zhao S, Wang FT, Zhou TT, Liu B and Bao JK: Programmed cell death pathways in cancer: A review of apoptosis, autophagy and programmed necrosis. Cell Prolif 45 487-498, 2012

9. Klionsky DJ, Abdelmohsen K, Abe A, Abedin MJ, Abeliovich $\mathrm{H}$, Acevedo Arozena A, Adachi H, Adams CM, Adams PD, Adeli K, et al: Guidelines for the use and interpretation of assays for monitoring autophagy (3rd edition). Autophagy 12: 1-222, 2016.

10. Rao S, Tortola L, Perlot T, Wirnsberger G, Novatchkova M, Nitsch R, Sykacek P, Frank L, Schramek D, Komnenovic V, et al: A dual role for autophagy in a murine model of lung cancer. Nat Commun 5: 3056, 2014

11. Ren JH, He WS, Nong L, Zhu QY, Hu K, Zhang RG, Huang LL, Zhu F and Wu G: Acquired cisplatin resistance in human lung adenocarcinoma cells is associated with enhanced autophagy. Cancer Biother Radiopharm 25: 75-80, 2010.

12. White E: The role for autophagy in cancer. J Clin Invest 125 : 42-46, 2015.

13. Sui X, Chen R, Wang Z, Huang Z, Kong N, Zhang M, Han W, Lou F, Yang J, Zhang Q, et al: Autophagy and chemotherapy resistance: A promising therapeutic target for cancer treatment Cell Death Dis 4: e838, 2013

14. Kroemer G and Levine B: Autophagic cell death: The story of a misnomer. Nat Rev Mol Cell Biol 9: 1004-1010, 2008.

15. Shimizu S, Yoshida T, Tsujioka M and Arakawa S: Autophagic cell death and cancer. Int J Mol Sci 15: 3145-3153, 2014.

16. Zeng $X$ and Kinsella TJ: Impact of autophagy on chemotherapy and radiotherapy mediated tumor cytotoxicity: 'To Live or not to Live'. Front Oncol 1: 30, 2011.

17. Chang Y, Yan W, He X, Zhang L, Li C, Huang H, Nace G, Geller DA, Lin J and Tsung A: miR-375 inhibits autophagy and reduces viability of hepatocellular carcinoma cells under hypoxic conditions. Gastroenterology 143: 177-187.e8, 2012.

18. Livak KJ and Schmittgen TD: Analysis of relative gene expression data using real-time quantitative PCR and the 2(-Delta Delta C(T)) method. Methods 25: 402-408, 2001.

19. Zhang L, Cardinal JS, Pan P, Rosborough BR, Chang Y, Yan W, Huang H, Billiar TR, Rosengart MR and Tsung A: Splenocyte apoptosis and autophagy is mediated by interferon regulatory factor 1 during murine endotoxemia. Shock 37: 511-517, 2012.

20. Zhang L, Cardinal JS, Bahar R, Evankovich J, Huang H, Nace G, Billiar TR, Rosengart MR, Pan P and Tsung A: Interferon regulatory factor-1 regulates the autophagic response in LPS-stimulated macrophages through nitric oxide. Mol Med 18: 201-208, 2012

21. Kitazumi I and Tsukahara M: Regulation of DNA fragmentation: The role of caspases and phosphorylation. FEBS J 278: 427-441, 2011.

22. Yang ZJ, Chee CE, Huang S and Sinicrope FA: The role of autophagy in cancer: Therapeutic implications. Mol Cancer Ther 10: 1533-1541, 2011.

23. Zhu K, Dunner K Jr and McConkey DJ: Proteasome inhibitors activate autophagy as a cytoprotective response in human prostate cancer cells. Oncogene 29: 451-462, 2010.

24. Siegel RL, Miller KD and Jemal A: Cancer statistics, 2016. CA Cancer J Clin 66: 7-30, 2016.

25. de Castria TB, da Silva EM, Gois AF and Riera R: Cisplatin versus carboplatin in combination with third-generation drugs for advanced non-small cell lung cancer. Cochrane Database Syst Rev: CD009256, 2013.

26. Claerhout S, Verschooten L, Van Kelst S, De Vos R, Proby C Agostinis P and Garmyn M: Concomitant inhibition of AKT and autophagy is required for efficient cisplatin-induced apoptosis of metastatic skin carcinoma. Int J Cancer 127: 2790-2803, 2010.
27. Kaminskyy VO, Piskunova T, Zborovskaya IB, Tchevkina EM and Zhivotovsky B: Suppression of basal autophagy reduces lung cancer cell proliferation and enhances caspase-dependent and -independent apoptosis by stimulating ROS formation. Autophagy 8: 1032-1044, 2012.

28. Zou Y, Ling YH, Sironi J, Schwartz EL, Perez-Soler R and Piperdi B: The autophagy inhibitor chloroquine overcomes the innate resistance of wild-type EGFR non-small-cell lung cancer cells to erlotinib. J Thorac Oncol 8: 693-702, 2013.

29. Liu F, Liu D, Yang Y and Zhao S: Effect of autophagy inhibition on chemotherapy-induced apoptosis in A549 lung cancer cells. Oncol Lett 5: 1261-1265, 2013.

30. Janku F, McConkey DJ, Hong DS and Kurzrock R: Autophagy as a target for anticancer therapy. Nat Rev Clin Oncol 8: 528-539, 2011.

31. Eisenberg-Lerner A, Bialik S, Simon HU and Kimchi A: Life and death partners: Apoptosis, autophagy and the cross-talk between them. Cell Death Differ 16: 966-975, 2009.

32. Zhang YH, Wu YL, Tashiro S, Onodera S and Ikejima T: Reactive oxygen species contribute to oridonin-induced apoptosis and autophagy in human cervical carcinoma HeLa cells. Acta Pharmacol Sin 32: 1266-1275, 2011.

33. Viola G, Bortolozzi R, Hamel E, Moro S, Brun P, Castagliuolo I, Ferlin MG and Basso G: MG-2477, a new tubulin inhibitor, induces autophagy through inhibition of the Akt/mTOR pathway and delayed apoptosis in A549 cells. Biochem Pharmacol 83: 16-26, 2012.

34. Driscoll JJ and Chowdhury RD: Molecular crosstalk between the proteasome, aggresomes and autophagy: Translational potential and clinical implications. Cancer Lett 325: 147-154, 2012.

35. Wu HM, Jiang ZF, Ding PS, Shao LJ and Liu RY: Hypoxia-induced autophagy mediates cisplatin resistance in lung cancer cells. Sci Rep 5: 12291, 2015.

36. Apel A, Herr I, Schwarz H, Rodemann HP and Mayer A: Blocked autophagy sensitizes resistant carcinoma cells to radiation therapy. Cancer Res 68: 1485-1494, 2008.

37. Livesey KM, Tang D, Zeh HJ and Lotze MT: Autophagy inhibition in combination cancer treatment. Curr Opin Investig Drugs 10: 1269-1279, 2009

38. Han W, Pan H, Chen Y, Sun J, Wang Y, Li J, Ge W, Feng L, Lin $\mathrm{X}$, Wang $\mathrm{X}$, et al: EGFR tyrosine kinase inhibitors activate autophagy as a cytoprotective response in human lung cancer cells. PLoS One 6: e18691, 2011.

39. Jiang ZF, Shao LJ, Wang WM, Yan XB and Liu RY: Decreased expression of Beclin-1 and LC3 in human lung cancer. Mol Biol Rep 39: 259-267, 2012.

40. Chen Z, Li Y, Zhang C, Yi H, Wu C, Wang J, Liu Y, Tan J and Wen J: Downregulation of Beclin 1 and impairment of autophagy in a small population of colorectal cancer. Dig Dis Sci 58: 2887-2894, 2013

41. Shen Y, Li DD, Wang LL, Deng R and Zhu XF: Decreased expression of autophagy-related proteins in malignant epithelial ovarian cancer. Autophagy 4: 1067-1068, 2008.

42. Zhou WH, Tang F, Xu J, Wu X, Yang SB, Feng ZY, Ding YG, Wan XB, Guan Z, Li HG, et al: Low expression of Beclin 1, associated with high $\mathrm{Bcl}-\mathrm{xL}$, predicts a malignant phenotype and poor prognosis of gastric cancer. Autophagy 8: 389-400, 2012.

43. Wang X, Du Z, Li L, Shi M and Yu Y: Beclin 1 and p62 expression in non-small cell lung cancer: Relation with malignant behaviors and clinical outcome. Int J Clin Exp Pathol 8: 10644-10652, 2015

44. Scarlatti F, Maffei R, Beau I, Codogno P and Ghidoni R: Role of non-canonical Beclin 1-independent autophagy in cell death induced by resveratrol in human breast cancer cells. Cell Death Differ 15: 1318-1329, 2008.

45. Chang SH, Minai-Tehrani A, Shin JY, Park S, Kim JE, Yu KN, Hong SH, Hong CM, Lee KH, Beck GR Jr and Cho $\mathrm{MH}$ : Beclin1-induced autophagy abrogates radioresistance of lung cancer cells by suppressing osteopontin. J Radiat Res 53: 422-432, 2012.

46. Michaud M, Martins I, Sukkurwala AQ, Adjemian S, Ma Y, Pellegatti P, Shen S, Kepp O, Scoazec M, Mignot G, et al: Autophagy-dependent anticancer immune responses induced by chemotherapeutic agents in mice. Science 334: 1573-1577, 2011. 